\title{
Ethiopia's Antibiotic Footprint: Estimate of National Antibiotic Consumption Using 2018 Data
}

Girma Gutema ( $\sim$ girmabbaacabsaa@gmail.com )

University of Oslo and Rift Valley University

\section{Seid Ali}

University of Basel

\section{Ephrem Engidawork}

Addis Ababa University

\section{Mirgissa Kaba}

Addis Ababa University

\section{Else-Lydia Toverud}

University of Oslo

\section{Research}

Keywords: antibiotic footprint, antibiotic consumption, Ethiopia

Posted Date: February 5th, 2021

DOI: https://doi.org/10.21203/rs.3.rs-186995/v1

License: (9) This work is licensed under a Creative Commons Attribution 4.0 International License.

Read Full License 


\section{Abstract}

The processes involving resistance development against antibiotics have historically been part of the Darwinian evolution. But in the backdrop of this evolutionary reality, the increasing use of antibiotics in modern medicine, particularly in post-penicillin discovery era, has intensified the selection pressures with an acute gear up rather than as part of the so slow and natural evolutionary process that selects for enhanced fitness for survival. Two major recommendations were made in the past years to tackle this challenge: 1) incentivizing the pharmaceutical industry to invest more on research and development endeavors, so that they come up with new and novel antibiotics; 2 ) implementing antimicrobial stewardship programs in healthcare systems.

In the current study, the third and the emerging approach - the idea of antibiotic footprint - was employed as a communication tool that targets individual consumers of antibiotics to tackle the problems of their misuse and overuse.

A total of 698.2 tons of antibiotics were used in Ethiopia in 2018, and the per capita consumption of antibiotics was 5.8 grams per person. Penicillins with extended spectrum (J01CA) and beta-lactamaseresistant penicillins (J01CF) were the most commonly utilized classes of antibiotics which accounted for, respectively, $38.3 \%$ and $20.8 \%$ of all antibiotics used in the country's public health sector. Hubs in Addis Ababa (14\%) and Hawassa (12\%) topped the overall antibiotic consumptions in the country. Contrarily, hubs in Gambella and Semera received relatively smaller quantities of antibiotics, with totals of 4.8 tons $(0.9 \%)$ and 10.2 tons $(1.9 \%)$, respectively.

\section{Full Text}

This preprint is available for download as a PDF.

\section{Figures}





Figure 1

A conceptual figure for carbon footprint and antibiotic footprint, showing holistic approaches to the former (left) and the later (right), respectively [source: MARU]. 




\section{Figure 2}

Percentages of antibiotic classes delivered to regional hubs based on the quantifications of their annual demands for the year 2018 




Figure 3

Annual consumptions of antibiotics (in tons) in the human health and livestock sectors in Ethiopia, 2018 


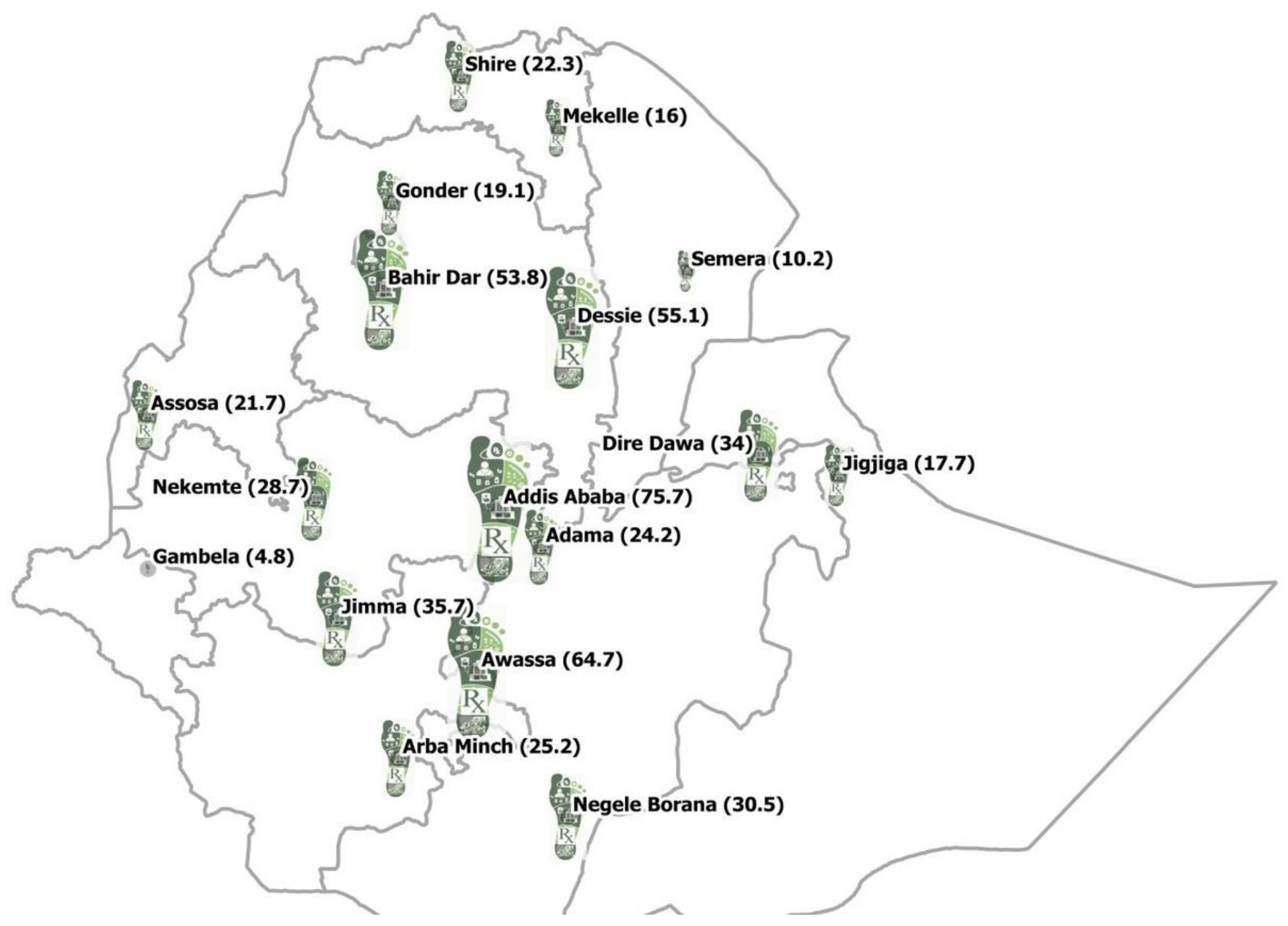

Figure 4

Quantities of antibiotics (in tons) consumed at EPSA's regional hubs in 2018. Note: The designations employed and the presentation of the material on this map do not imply the expression of any opinion whatsoever on the part of Research Square concerning the legal status of any country, territory, city or area or of its authorities, or concerning the delimitation of its frontiers or boundaries. This map has been provided by the authors. 


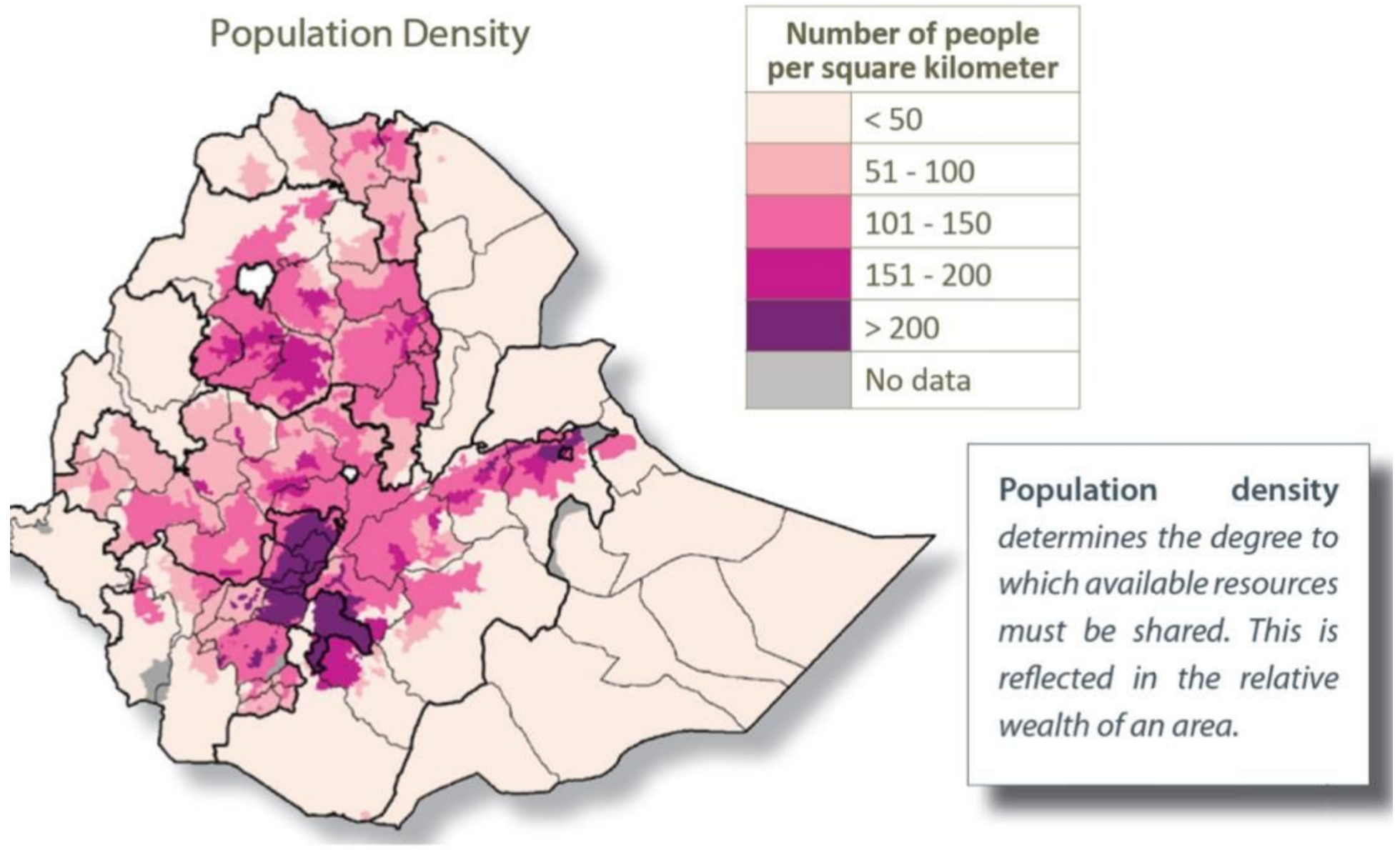

Figure 5

Population settlement density in Ethiopia [source: LSE] Note: The designations employed and the presentation of the material on this map do not imply the expression of any opinion whatsoever on the part of Research Square concerning the legal status of any country, territory, city or area or of its authorities, or concerning the delimitation of its frontiers or boundaries. This map has been provided by the authors. 